\title{
Influence of very low dietary intake of marine oil on some functional aspects of immune cells in healthy elderly people
}

\author{
Shaliha Bechoua ${ }^{1}$, Madeleine Dubois ${ }^{1}$, Evelyne Véricel ${ }^{1}$, Paul Chapuy ${ }^{2}$, \\ Michel Lagarde ${ }^{1}$ and Annie-France Prigent ${ }^{1} *$ \\ ${ }^{1}$ Institut National de la Santé et de la Recherche Médicale U352, Laboratoire de Biochimie et Pharmacologie, \\ INSA-Lyon, France \\ ${ }^{2}$ Service de Gériatrie, Hôpital des Charpennes, Villeurbanne, France \\ (Received 7 May 2002 - Revised 21 October 2002 - Accepted 5 November 2002)
}

\begin{abstract}
Ageing is a multifactorial process involving decreased antioxidant defences and immune functions. $n-3$ Polyunsaturated fatty acids have been associated with human health benefits, especially against inflammatory and autoimmune diseases. However, their immunomodulatory effects were usually observed with high dosages $(>2 \mathrm{~g} / \mathrm{d})$ known to increase lipid peroxidation. In contrast, very low doses, that may prevent lipid peroxidation, might affect the immune system differently. To study the latter hypothesis further, we investigated whether the supplementation of healthy elderly people with very low doses of marine oil (MO), a docosahexaenoate (DHA)- and eicosapentaenoate (EPA)-rich triacylglycerol, was able to affect lymphocyte proliferation and biochemical markers known to be altered with age. In a randomized, double-blind design, twenty healthy elderly subjects were assigned to a placebo group $(600 \mathrm{mg}$ sunflower oil/d) or to a group consuming $600 \mathrm{mg} \mathrm{MO} / \mathrm{d}$ providing $150 \mathrm{mg} \mathrm{DHA}+$ $30 \mathrm{mg}$ (EPA) for 6 weeks. At day 42, the proliferative responses of lymphocytes to several mitogens were significantly $(P<0 \cdot 01)$ decreased in the MO group compared with control values. This was accompanied by a slight lowering of their cytosolic cyclic nucleotide phosphodiesterase (PDE) activity, a marked and significant $(P<0.05)$ increase of their particulate PDE activity $(+56-57 \%)$ and a slight but significant $(P<0.05)$ increase in cyclic nucleotide intracellular levels. At the same time, the glutathione peroxidase activity was markedly and significantly $(P<0.01)$ depressed in the MO group. None of these modifications could be seen in the placebo group. Collectively, these results demonstrate that even very low doses of $n-3$ fatty acids are sufficient to affect the immune responses of elderly subjects.
\end{abstract}

n-3 Fatty acids: Docosahexaenoic acid: Lymphocyte proliferation: Cyclic nucleotide phosphodiesterase: Glutathione peroxidase: Immune function in human ageing

Epidemiological observations suggest that $n-3$ polyunsaturated fatty acids (PUFA) from marine oil (MO) have beneficial effects on the prevention and treatment of chronic cardiovascular and inflammatory diseases (Simopoulos, 1991; Endres et al. 1995; Meydani, 1996). However, the effects of $n-3$ fatty acids on functional variables of the human immune system remain a focus of research interests. Several studies indicate that the supplementation of human diets with PUFA modulates the immune system with either detrimental or beneficial effects. Thus, dietary lipids have been shown to promote the development and subsequent progression of breast and prostatic cancer (Rose, 1997) and to improve the condition of patients suffering from disorders involving over-reactive immune responses (Fortin et al. 1995; Mohan \& Das, 1997). Conversely, dietary supplementation with $n-3$ fatty acids has been shown to prevent trauma-induced immunosuppression (Ayala \& Chaudry, 1995). The amount and the nature of lipids are both important for the immunomodulation. In particular, PUFA seem to affect cell-mediated immunity. Indeed, fish oil supplementation of human and animal diets has been shown to decrease interleukin 2 production and $\mathrm{T}$ cell mitogen-induced proliferation, indicating an overall decreased $\mathrm{T}$ cell-mediated immune function (Endres et al. 1993; Calder et al. 2002). In vitro, PUFA, either from the $n-6$ or the $n-3$ families, inhibit the

\footnotetext{
Abbreviations: DHA, docosahexaenoic acid; EPA, eicosapentaenoic acid; GSH-Px, glutathione peroxidase; MO, marine oil; PA, phosphatidic acid; PBMN, peripheral blood mononuclear cells; PDE, phosphodiesterase; PE, phosphatidylethanolamine PUFA, polyunsaturated fatty acid; SO, sunflower oil. * Corresponding author: Dr Annie-France Prigent, fax +33 4724385 24, email prigent@insa-lyon.fr
} 
mitogen-induced proliferation of murine or human lymphocytes (Calder \& Newsholme, 1992; Joulain et al. 1995; Calder et al. 2002). Many effects of dietary n-3 fatty acids may be explained by their ability to alter arachidonic acid metabolism and eicosanoid synthesis (Miles \& Calder, 1998). In addition, they can also alter membrane-associated functions (Murphy, 1990) and cytokine gene expression in cells of the immune system (Miles \& Calder, 1998).

Ageing is associated with a decrease in both immune responses and antioxidant defences (Burns \& Goodwin, 1997; Beckman \& Ames, 1998). Among the age-related functional changes, the depressed proliferative response of lymphocytes to plant lectins and mitogens in vitro has been well characterized both in human subjects and rodents (Solana et al. 1991; Kariv et al. 1992; Burns \& Goodwin, 1997). On the other hand, a decrease in the antioxidant defences leading to increased oxidative protein damage and lipid peroxidation has been reported in various tissues of old animals (Tian et al. 1998). Meskini et al. (1993) have shown that the glutathione peroxidase (GSH-Px) activity of human peripheral blood mononuclear cells (PBMN) decreased with age. This enzymatic defect, which may influence the lymphoproliferative response in several ways, was accompanied by an age-related increase in the oxygenated metabolism of endogenous arachidonic acid by lipoxygenases. Another enzymatic defect that has been associated with ageing was a decrease in lymphocyte cyclic nucleotide phosphodiesterase (PDE) activity (Meskini et al. 1990). As cyclic AMP is a potent suppressor of most immune responses (Skalhegg et al. 1992), it can be assumed that a defect in lymphocyte cAMP hydrolysing activity would contribute to the impaired lymphoproliferative responses to mitogens observed in elderly people.

Most human nutritional studies have shown that supplementation of the diets with $n-3$ PUFA enhanced cellular lipid hydroperoxide production (Nair et al. 1993). These studies generally used high dietary intake (usually $>2 \mathrm{~g}$ fatty acids/d). However, it has also been shown that very low doses of $n-3$ PUFA can, paradoxically, protect cells from peroxidative stress (Calzada et al. 1992). On the other hand, we have also observed that $n-3$ fatty acids, mainly docosahexaenoic acid (DHA), were able to increase both PDE and GSH-Px activities of human PBMN in vitro when added to culture medium (Joulain et al. 1994, 1995). Taken together, the results discussed here led us to carry out the present nutritional study in elderly people. The aim of the present study was to investigate the possibility of modulating the reactivity of PBMN by the ingestion of low doses of MO $(600 \mathrm{mg} / \mathrm{d}$, providing $150 \mathrm{mg}$ DHA $+30 \mathrm{mg}$ eicosapentaenoic acid $($ EPA)/d). We studied the influence of dietary n-3 PUFA supplementation on the lymphoproliferative response and on the enzymatic targets previously shown to be altered with age.

Thus, cyclic AMP and cyclic GMP-PDE activities, GSHPx activity, cyclic nucleotide levels (cAMP and cGMP), the proliferative response to the plant lectins concanavalin $\mathrm{A}$ and phytohaemagglutinin $\mathrm{A}$ and to the anti-CD3 antibody OKT3 were determined in PBMN from elderly people before and after supplementation for 6 weeks with $600 \mathrm{mg}$ MO or $600 \mathrm{mg}$ sunflower oil (SO)/d (placebo).

\section{Subjects and methods}

\section{Subjects and experimental design}

The twenty subjects recruited for the study were healthy and non-institutionalized elderly people. They had no metabolic, malignant or clinically detected cardiovascular diseases. Each of them gave informed consent according to the guidelines of the French Ethical Committee. The mean age of the selected subjects (six men and fourteen women) was 75.6 (SD 4.1) (range 70-83) years. At the beginning of the study each of them had normal blood cell counts, packed cell volume (44.6 (SD 0.9) \%, n 20), mild hypercholesterolaemia (6.6 (SD 1.4) $\mathrm{mM}, n$ 20), normal triacylglycerolaemia (1.4 (SD 0.7$) \mathrm{mM}, n 20)$ and glycaemia (5.5 (SD 0.7) $\mathrm{mm}, n$ 20). Their mean systolic and diastolic blood pressures were 145 (SD 12) and 81 (SD 2) $\mathrm{mmHg}$ respectively ( $n$ 20). In a double-blind design, subjects were randomly assigned to two groups. The placebo group (four men and six women) ingested $600 \mathrm{mg} \mathrm{SO} / \mathrm{d}$ for 6 weeks. The treated group (two men and eight women) ingested $600 \mathrm{mg}$ MO (RO-PUFA ${ }^{\circledR}$; Roche, Basle, Switzerland)/d, for the same period. The fatty acid composition of the oils determined by GC on total lipid extracts is shown in Table 1. This amount of MO provides $150 \mathrm{mg}$ DHA + $30 \mathrm{mg}$ EPA. The dietary supplements were administered in indistinguishable soft gelatine capsules that each contained $600 \mathrm{mg}$ oil and adequate amounts of vitamin $\mathrm{E}$ as an antioxidant $(0.17 \mathrm{mg} \alpha$-tocopherol for the placebo and $0.54 \mathrm{mg}$ for the MO, which represents $<5 \%$ of the normal vitamin $\mathrm{E}$ intake). The habitual fish intake among elderly people in France is estimated to be about $20 \mathrm{~g} / \mathrm{d}$ according to the Agence Française de Sécurité Sanitaire des Aliments (Maisons-Alfort, France), providing $0.10 \mathrm{~g}$ DHA and $0.05 \mathrm{~g} \mathrm{EPA} / \mathrm{d}$. Thus the amount of DHA + EPA provided by the supplementation was in the range of the habitual nutritional intake. Each individual was asked not to deviate from their regular habits during the study period and to ingest one capsule per $\mathrm{d}$ with their principal meal. The dietary supplements

Table 1. Fatty acid composition of the oils*

\begin{tabular}{lcccccccc}
\hline & \multicolumn{7}{c}{ Fatty acid (mol/100 mol total fatty acids) } \\
\cline { 2 - 9 } Treatment & Palmitic & Palmitoleic & Stearic & Oleic & Linoleic & Arachidonic & EPA & DHA \\
\hline Sunflower oil (placebo) & 5.9 & 0.1 & 3.8 & 23.0 & 65.9 & 0 & 0 & 0 \\
Marine oil & 19.9 & 5.6 & 5.5 & 13.5 & 2.0 & 1.8 & 5.4 & 25.6 \\
\hline
\end{tabular}

EPA, eicosapentaenoic; DHA, docosahexaenoic.

*Values were determined by GC analysis of total lipid extracts. 
were manufactured by Imedex (Lyon, France). Blood samples were drawn on day 0 and day 42 for biochemical analyses. The subjects had not taken any drugs at least $10 \mathrm{~d}$ before the initial blood sampling and during the test period.

\section{Peripheral blood mononuclear cell isolation}

Venous blood was drawn from an antecubital vein into vacutainers (Becton Dickinson, Meylan, France) containing citric acid-sodium citrate-dextrose anticoagulant. The platelet-rich plasma was removed after initial centrifugation (120 $\mathrm{g}$ for $18 \mathrm{~min}$ ) and erythrocytes were passively sedimented for $30 \mathrm{~min}$ at $37^{\circ} \mathrm{C}$ after addition of dextran (final concentration $10 \mathrm{~g} / \mathrm{l}$; Sigma-Chimie, L'Isle d'Abeau, France) prepared in buffered saline $(9 \mathrm{~g} \mathrm{NaCl} /$ 1), $\mathrm{pH} 7.4$ containing $1 \mathrm{mm-EDTA}$. The leucocyte-rich supernatant fraction was then removed, layered onto Histopaque (density $1.077 \mathrm{~g} / \mathrm{ml} \mathrm{Sigma-Chimie)} \mathrm{and} \mathrm{centrifuged}$ at $600 \mathrm{~g}$ for $15 \mathrm{~min}$ at $20^{\circ} \mathrm{C}$. The resulting mononuclear fraction was washed with PBS and then, washed twice with RPMI 1640 (Gibco, Cergy Pontoise, France) by low-speed centrifugation in order to eliminate the contaminating platelets more thoroughly. Cell viability, established by the Trypan Blue exclusion test, was always $>95 \%$. PBMN were then adjusted to a concentration of $20 \times 10^{6}$ cells/ml RPMI 1640 (with $20 \mathrm{mM}-4$-(2-hydroxyethyl)-1piperazine-ethanesulfonic acid (HEPES) and bicarbonate) medium.

\section{Biochemical analyses}

Cell lysis. For enzymatic activity determinations, pelleted PBMN were washed with Phillips' buffer and disrupted by glycerol lysis as previously described (Meskini et al. 1992). After glycerol treatment, the cells were pelleted at $900 \mathrm{~g}$ for $10 \mathrm{~min}$, resuspended in lysis buffer $(20$ mM-4-(2-hydroxyethyl)-1-piperazine-ethanesulfonic acid (HEPES), $25 \mathrm{~mm}$-sucrose, $0 \cdot 1 \mathrm{~mm}$-ethylene glycol- $O,-O^{\prime}$ bis-(2-amino-ethyl)- $N, N, N^{\prime}, N^{\prime}$-tetraacetic acid (EGTA), $0.06 \mathrm{mM}$-phenyl methane sulfonylfluoride, $10000 \mathrm{U}$ aprotinin/l, $2 \mathrm{mg}$ pepstatin $\mathrm{A} / \mathrm{l}, \mathrm{pH} \mathrm{7.4)}$ and stored frozen at $-30^{\circ} \mathrm{C}$. After thawing, the cells were homogenized in a glass-teflon homogenizer (forty strokes at maximal speed) and homogenates were centrifuged at $100000 \mathrm{~g}$ for $60 \mathrm{~min}$.

Cyclic nucleotide phosphodiesterase assays. PDE activities of supernatant and pellet fractions were measured according to a two-step radioisotopic method lysis as previously described (Meskini et al. 1992). Results are expressed as pmol cAMP or cGMP hydrolysed/min per $\mathrm{mg}$ protein. Protein was assayed according to Bradford (1976) using bovine serum albumin as a standard.

Glutathione peroxidase assay. GSH-Px activity was determined according to the method of Paglia \& Valentine (1967) as previously described (Meskini et al. 1993). Results are expressed as nmol NADPH oxidized/min per $\mathrm{mg}$ protein using an extinction molar coefficient of $0.0622 / \mathrm{mm}^{2}$ per $\mu \mathrm{mol}$ for NADPH. Inhibition of $90-95 \%$ was consistently observed in the presence of 0.2 mM-mercaptosuccinic acid, which indicates a Se-dependent GSH-Px activity.
Proliferative response of peripheral blood mononuclear cells to concanavalin $A$, phytohaemagglutinin $A$ and OKT3. PBMN were cultured in microtitre culture plates at $2 \times 10^{5}$ cells per well in a final volume of $200 \mu \mathrm{l}$ RPMI 1640 supplemented with $2 \mathrm{mM}$-glutamine, $100 \mathrm{mg}$ streptomycin $+100000 \mathrm{U}$ penicillin/l and decomplemented fetal calf serum (100 ml/1; Gibco, Cergy Pontoise, France). At the initiation of the culture, $5 \mathrm{mg}$ concanavalin $\mathrm{A} / \mathrm{l}$ or $1 \mathrm{mg}$ phytohaemagglutinin/l (Sigma-Chimie) or $100 \mu \mathrm{g}$ OKT3/1 (Cilag Laboratories, Levallois Perret, France) were added to the cell suspensions. Control cells were incubated in the same conditions without mitogen. Cultures were incubated at $37^{\circ} \mathrm{C}$ in an air- $\mathrm{CO}_{2}(95: 5)$ atmosphere. After $48 \mathrm{~h}$ incubation, $18.5 \mathrm{kBq}\left[{ }^{3} \mathrm{H}\right]$ thymidine per well (Amersham, Les Ulis, France) were added to the cultures and the cells were incubated for a further $24 \mathrm{~h}$. The cells were then harvested (Cell-Harvester Autowash, 2000; Dynatech, Fisher-Bioblock Scientific, Illkirch, France) onto glass-fibre filters. Filters were washed and dried. The radioactivity incorporated in the cells was measured by liquid scintillation counting.

Cyclic nucleotide determinations. The cAMP and cGMP content of human PBMN was measured by radioimmunoassay ${ }^{125}$ I-labelled cAMP and ${ }^{125}$ I-labelled cGMP radioimmunoassay kits; Perkin-Elmer Life Sciences, Les Ulis, France). PBMN $\left(20 \times 10^{6}\right.$ cells $\left./ \mathrm{ml}\right)$ were allowed to rest for $2 \mathrm{~h}$ at $37^{\circ} \mathrm{C}$ in borosilicate glass tubes (Corning, VWR Int., Funtenay-sous-Bois, France). Incubations were terminated by boiling the samples for $2 \mathrm{~min}$. Proteins were removed by centrifugation $(4500 \mathrm{~g}$ for $10 \mathrm{~min}$ ), supernatant fractions were diluted as required in the immunoassay buffers and cAMP and cGMP were assayed according to the manufacturer's recommendations.

Lipid analyses. Plasma was acidified to $\mathrm{pH} \mathrm{3-4}$ and lipids were extracted with chloroform-ethanol $(6: 3, \mathrm{v} / \mathrm{v})$ in the presence of $50 \mu \mathrm{M}$-butylhydroxylated toluene, according to the method of Boukhchache \& Lagarde (1982). The different lipid classes were separated on silica gel G60 plates (Merck, Darmstadt, Germany) with the solvent system hexane-diethyl ether-acetic acid (80:20:1, by vol.). The silica gel areas corresponding to phospholipids, non-esterified fatty acids, triacylglycerols and cholesteryl esters were scraped off and transmethylated. Briefly, 1 vol. $\mathrm{H}_{2} \mathrm{SO}_{4}(50 \mathrm{ml} / \mathrm{l}$ methanol) was added to the scraped silica gel and transmethylation was carried out under an $\mathrm{N}_{2}$ atmosphere at $100^{\circ} \mathrm{C}$ for $90 \mathrm{~min}$ in screw-capped tubes. The reaction was terminated by the addition of 1.5 vol. $\mathrm{K}_{2} \mathrm{CO}_{3}(50 \mathrm{~g} / \mathrm{l})$ and the fatty acid methyl esters were extracted with isooctane and stored at $-30^{\circ} \mathrm{C}$ under $\mathrm{N}_{2}$. The fatty acid methyl esters from cholesteryl esters were purified on TLC with the solvent system hexane-diethyl ether $(80: 20, \mathrm{v} / \mathrm{v})$ in order to eliminate the contaminating cholesterol. The purified fatty acid methyl esters were scraped off and extracted with diethyl ether-methanol $(9: 1, \mathrm{v} / \mathrm{v})$, then evaporated and dissolved in isooctane and stored at $-30^{\circ} \mathrm{C}$ under $\mathrm{N}_{2}$. The non-esterified fatty acids from plasma were methylated with approximately $250 \mu \mathrm{l}$ diazomethane at room temperature and darkness for $15 \mathrm{~min}$. The diazomethane was evaporated to dryness under reduced pressure and the extracts were dissolved in isooctane for GC analysis. The fatty acid 
methyl esters from phospholipids, non-esterified fatty acids, triacylglycerols and cholesteryl esters fractions were analysed using a Perkin-Elmer chromatograph model 5830, equipped with a capillary column $(30 \mathrm{~m} \times 0.32 \mathrm{~mm}$; Supelco, Bellefonte, CA, USA) and a flame ionization detection. The column was two-step programmed from 135 to $160^{\circ} \mathrm{C}$ at $2^{\circ} \mathrm{C} / \mathrm{min}$ and from 160 to $205^{\circ} \mathrm{C}$ at $1.5^{\circ} \mathrm{C} / \mathrm{min}$, the detection temperature was maintained at $250^{\circ} \mathrm{C}$. The vector gas was $\mathrm{He}$ at a pressure of $5.52 \mathrm{kPa}(0.8 \mathrm{psi})$. Peaks were identified using standard fatty acid methyl esters.

\section{Statistical analyses}

Each set of variables measured in the present study had normal distribution according to the Lilliefors' test for normality. All values are expressed as means with their standard errors. Data were analysed by Student's paired $t$ test comparing values of the various variables on day 0 and day 42 , each subject acting as his own control. This made the calculations independent of possible variations between subjects at day 0 .

\section{Results}

Both dietary supplements (SO and MO) were well tolerated and compliance, based on capsule consumption, was excellent in both groups. There were no significant changes in haematological variables and in serum glucose, triacylglycerol and cholesterol after dietary intervention with both oils (results not shown). Mean systolic blood pressure was significantly decreased by MO intake from 145.5 (SEM $5 \cdot 1$ ) at day 0 to 131.5 (SEM 4.5) $\mathrm{mmHg}$ at day 42 ( $n 10$, $P=0.001)$, whereas no change was observed in the placebo
(SO) group (144.5 (SEM 2.6) at day $0 v .142 .5$ (SEM 3.8) $\mathrm{mmHg}$ at day 42 ( $n$ 10, NS). In contrast, the diastolic blood pressure was not modified at the end of the treatment either in the placebo (SO) group (80 (SEM 3) at day $0 v .77$ (SEM 2$) \mathrm{mmHg}$ at day $42(n 10, \mathrm{NS})$ or in the MO group (82 (SEM 1) at day 0 v. 78 (SEM 2) $\mathrm{mmHg}$ at day 42 ( $n$ 10, NS).

The fatty acid composition of phospholipids, triacylglycerols, sterol esters and non-esterified fatty acids in the plasma of the elderly people were analysed before (day 0) and after (day 42) ingestion of $600 \mathrm{mg} \mathrm{MO}$ or SO/d. At the end of the supplementation period, no significant modifications in the fatty acid composition of plasma phospholipids, triacylglycerols and free fatty acids were observed either in the $\mathrm{MO}$ or in the placebo group ( $\mathrm{SO}$; results not shown). The only changes found were in plasma sterol esters (Table 2). An increase in the proportion of DHA was observed at the end of the supplementation period, the largest variation occurring in the MO group (+63\%, $P=0.002)$ compared with the placebo group (+ $23 \%$, NS). Thus, the low doses of MO used in the present study proved unable to induce a major enrichment in $n-3$ fatty acids of the main plasma lipids. Although we did not analyse the fatty acid composition of PBMN phospholipids due to an insufficient amount of cells, parallel investigations have been performed on platelets. Interestingly, changes have been observed only in phosphatidylethanolamine (PE) of platelets from subjects ingesting the MO. In this group, the DHA content increased significantly from 2.7 at day 0 to $3.4 \mathrm{~mol} / 100 \mathrm{~mol}(+26 \%, P<0.001)$ at day 42. No other significant change in any other fatty acid could be observed whatever the phospholipid class considered (Véricel et al. 1999).

The proliferative responses of PBMN to concanavalin A, phytohaemagglutinin and OKT3 were examined before

Table 2. Fatty acid composition of plasma sterol esters (mol/100 mol total fatty acids) at baseline (day 0) and after 6 weeks supplementation (day 42) in the sunflower oil- (placebo) and marine oil-groups $\dagger$

(Mean values with their standard errors for five subjects per group)

\begin{tabular}{|c|c|c|c|c|c|c|c|c|}
\hline \multirow[b]{3}{*}{ Fatty acid } & \multicolumn{4}{|c|}{ Sunflower oil (placebo) } & \multicolumn{4}{|c|}{ Marine oil } \\
\hline & \multicolumn{2}{|c|}{ Day 0} & \multicolumn{2}{|c|}{ Day 42} & \multicolumn{2}{|c|}{ Day 0} & \multicolumn{2}{|c|}{ Day 42} \\
\hline & Mean & SE & Mean & SE & Mean & SE & Mean & SE \\
\hline $16: 0$ & $12 \cdot 79$ & 0.39 & $12 \cdot 56$ & 0.23 & $12 \cdot 78$ & 0.36 & $12 \cdot 68$ & 0.57 \\
\hline $16: 1 n-7$ & $3 \cdot 80$ & 0.48 & 3.45 & 0.29 & 3.70 & 0.42 & 3.07 & 0.35 \\
\hline $18: 0$ & 0.73 & 0.07 & 0.81 & 0.05 & 0.71 & 0.07 & 0.85 & 0.07 \\
\hline $18: 1 n-9$ & $18 \cdot 66$ & 0.79 & $17 \cdot 56$ & 0.44 & $18 \cdot 67$ & $1 \cdot 12$ & $17 \cdot 34$ & $1 \cdot 17$ \\
\hline $18: 1 n-7$ & $1 \cdot 00$ & 0.09 & 1.06 & 0.07 & 0.95 & 0.06 & $1 \cdot 10$ & 0.07 \\
\hline $18: 2 n-6$ & 53.45 & 1.52 & $54 \cdot 03$ & 0.84 & $54 \cdot 60$ & 1.75 & $55 \cdot 11$ & $1 \cdot 84$ \\
\hline $18: 3 n-3$ & 0.31 & 0.05 & 0.34 & 0.04 & 0.30 & 0.05 & 0.39 & 0.04 \\
\hline $20: 3 n-6$ & 0.61 & 0.06 & 0.68 & 0.07 & 0.54 & 0.04 & 0.61 & 0.03 \\
\hline $20: 4 n-6$ & $7 \cdot 21$ & 0.46 & $7 \cdot 73$ & 0.48 & $6 \cdot 49$ & 0.44 & $7 \cdot 16$ & 0.44 \\
\hline $20: 5 n-3$ & 0.86 & $0 \cdot 10$ & 1.05 & 0.18 & 0.79 & 0.08 & 0.88 & 0.10 \\
\hline $22: 5 n-3$ & 0.02 & 0.01 & 0.04 & 0.01 & 0.01 & 0.01 & $0.06^{*}$ & 0.01 \\
\hline $22: 6 n-3$ & 0.56 & 0.05 & 0.70 & 0.05 & 0.46 & 0.05 & $0.75^{\star}$ & 0.04 \\
\hline Total saturated & $13 \cdot 52$ & 0.41 & $13 \cdot 37$ & $0 \cdot 24$ & $13 \cdot 49$ & 0.36 & $13 \cdot 53$ & 0.62 \\
\hline Total $n-6$ & $61 \cdot 27$ & 1.60 & $62 \cdot 43$ & 0.81 & 61.62 & 1.62 & $62 \cdot 88$ & 1.76 \\
\hline Total $n-3$ & $1 \cdot 76$ & 0.16 & $2 \cdot 14$ & 0.16 & 1.56 & 0.15 & $2 \cdot 08^{*}$ & 0.16 \\
\hline
\end{tabular}

Mean values were significantly different from those at day 0 for the same treatment group (Student's $t$ test): ${ }^{\star} P<0.05$.

†Sunflower oil-group (placebo), $600 \mathrm{mg}$ sunflower oil/d for 6 weeks; marine oil-group, $600 \mathrm{mg}$ marine oil for 6 weeks. For details of subjects and procedures, see p. 524 
(day 0) and after (day 42) supplementation of the diets of elderly people with low doses of SO or MO (Fig. 1). The proliferative responses to the three mitogens were significantly decreased in the MO group at day 42, compared with day 0 (concanavalin $\mathrm{A}-45 \%, P=0.01$; phytohaemagglutinin $-34 \%, P=0.008$; OKT3 $-34 \%, P=0.01)$. In the placebo group, a slight and non-significant decrease of the lymphoproliferative responses was observed at day 42, whatever the mitogen used. These results show that the ingestion of $180 \mathrm{mg} n-3$ fatty acids/d for 6 weeks decreased the lymphoproliferative responses of elderly people to mitogens.

No significant variations in the cytosolic cAMP- and cGMP-PDE activities of PBMN were observed after supplementation of the diets of elderly people, either in the $\mathrm{MO}$ or in the placebo (SO) group (Fig. 2 (a and b)). However, a slight decrease ( $-12 \%$ for cAMP-PDE and $-17 \%$ for cGMP-PDE) was observed in the MO group at day 42. In contrast, both cAMP- and cGMP-PDE activities were significantly increased in the particulate fraction of PBMN after 6 week supplementation of the diet with MO. cAMP-PDE activity significantly increased from 26.51 at day 0 to $41.51 \mathrm{pmol} / \mathrm{min}$ per $\mathrm{mg}$ protein $(+57 \%$, $P=0.03$ ) at day 42 (Fig. 2(c)), and cGMP-PDE activity

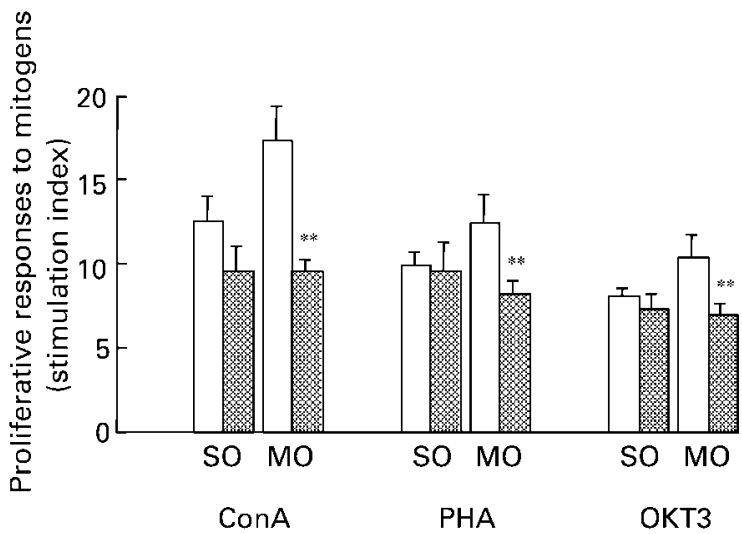

Fig. 1. Effects of marine oil (MO, $600 \mathrm{mg} / \mathrm{d}$ for 6 weeks) $v$. sunflower oil (SO (placebo), $600 \mathrm{mg} / \mathrm{d}$ for 6 weeks) on lymphocyte proliferation in elderly people. Before (day 0, ( $\square$ )) and after (day 42, (『)) supplementation, peripheral blood mononuclear cells were isolated and cultured in RPMI 1640 + fetal calf serum $(100 \mathrm{ml} / \mathrm{l})$ in the presence of either concanavalin A (ConA; $5 \mathrm{mg} / \mathrm{l})$, OKT3 $(100 \mu \mathrm{g} / \mathrm{l})$ or phytohaemagglutinin (PHA; $1 \mathrm{mg} / \mathrm{l})$. Control cells were incubated under the same conditions without mitogens. After $48 \mathrm{~h},\left[{ }^{3} \mathrm{H}\right]$ thymidine was added and the cells were incubated for a further $24 \mathrm{~h}$ prior to harvesting and radioactivity measurements. Results were expressed as the stimulation index: $\left[{ }^{3} \mathrm{H}\right]$ thymidine incorporated in the presence of mitogen $\left./{ }^{3} \mathrm{H}\right]$ thymidine incorporated in the absence of mitogen. Values are means with their standard errors represented by vertical bars for ten subjects (six replicates per subject) per group. For details of subjects and procedures, see p. 524. Mean values with their standard errors for $\left.{ }^{3} \mathrm{H}\right]$ thymidine incorporation (cpm) were as follows: unstimulated, SO (day 0) 2673 (SE 568), MO (day 0) 1799 (SE 238), SO (day 42) 2830 (SE 388), MO (day 42) 2091 (SE 278); ConA-stimulated, SO (day 0) 30162 (SE 6808), MO (day 0) 29098 (SE 5156), SO (day 42) 22865 (SE 2691), MO (day 42) 18528 (SE 2253); PHA-stimulated, SO (day 0) 24007 (SE 4732), MO (day 0) 24019 (SE 5156), SO (day 42) 20395 (SE 1475), MO (day 42) 17452 (SE 3371); OKT3-stimulated, SO (day 0) 21259 (SE 4639), MO (day 0) 17785 (SE 3047), SO (day 42) 17083 (SE 1702), MO (day 42) 14201 (SE 2529). Mean values were significantly different from those at day 0 (Student's test): ${ }^{\star \star} P \leq 0.01$. from 17.07 at day 0 to $26.61 \mathrm{pmol} / \mathrm{min}$ per $\mathrm{mg}$ protein $(+56 \%, P=0.02)$ at day 42 (Fig. 2(d)). In contrast, the particulate cAMP and cGMP-PDE activities were not altered by the SO intake (placebo group).

The ingestion of MO for 6 weeks also induced a slight but significant increase of both cAMP $(+19 \%, P=0.03)$ and cGMP $(+26 \%, P=0.05)$ levels in PBMN, whereas no significant variation was observed in the placebo group (Fig. 3).

GSH-Px, which catalyses the degradation of a variety of hydroperoxides including lipid hydroperoxides to the corresponding alcohols, may be considered as a marker of the antioxidant status of the cells. MO supplementation of the diet for 6 weeks decreased the GSH-Px activity of PBMN from 602.37 at day 0 to $373.60 \mathrm{nmol}$ NADPH oxidized/min per $\mathrm{mg}$ protein at day $42(-38 \%, P=0 \cdot 009)$. No significant alteration was observed in the placebo group (Fig. 4).

\section{Discussion}

Ageing is associated with a decline in immune function that may be related to the accompanying decrease of cell antioxidant defences (Solana et al. 1991; Burns \& Goodwin, 1997). Dietary intake of PUFA has also been associated with a decrease of immune cell functions (Calder et al. 2002). Most of the nutritional studies reported so far used large amounts of fish oil, usually providing $n-3$ fatty acid dosages $>2 \mathrm{~g} / \mathrm{d}$. Highly PUFA such as DHA and EPA, known to be very sensitive to peroxidation, have been shown to increase lipid radical formation induced by oxidant stress when incorporated in lipids of cell membranes (Alexander-North et al. 1994). However, in vitro experiments have also shown that low doses of n-3 PUFA may have opposite effects (Calzada et al. 1992; Bechoua et al. 1999). The present study was undertaken to investigate whether a supplementation of the diet of healthy elderly subjects with low doses of $n-3$ PUFA could affect the activity of enzymes known to be altered with age, such as PDE and GSH-Px, and to examine the possible consequences on lymphocyte proliferation.

The lack of large modification in the fatty acid composition of plasma lipids at the end of the supplementation period, either in the placebo group receiving $600 \mathrm{mg} \mathrm{SO} / \mathrm{d}$ for 6 weeks or in the MO group supplemented with $600 \mathrm{mg} \mathrm{MO} / \mathrm{d}$ providing $150 \mathrm{mg} \mathrm{DHA}+30 \mathrm{mg} \mathrm{EPA} / \mathrm{d}$, clearly indicates that the fatty acid doses used were sufficiently low not to alter drastically cell membrane lipids. The fact that the relative amount of DHA in plasma sterol esters and platelet PE was significantly $(P<0 \cdot 002)$ increased in the MO but not in the placebo (SO) group suggests that compliance obtained in the study was satisfactory. Another finding supporting compliance was the observation of a significant $(P<0.001)$ decrease in the systolic arterial blood pressure after 6 weeks of MO supplementation. Although such an effect was usually observed for $n-3$ fatty acid dosages $>2 \mathrm{~g} / \mathrm{d}$ in the mildly hypertensive adult population, about 10 -fold lower doses were needed in the elderly population (present study; Croset et al. 1990).

It is becoming clear that the consumption of diets that contain large amounts of fish oil-derived $n-3$ PUFA 
(a)

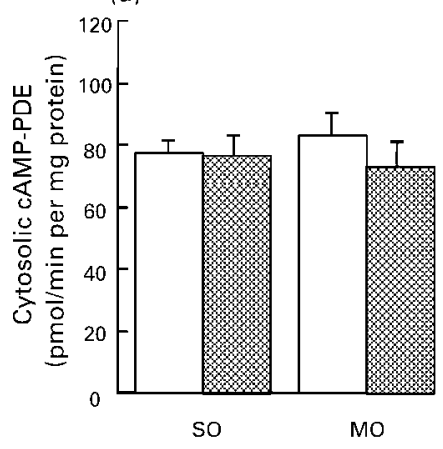

(c)

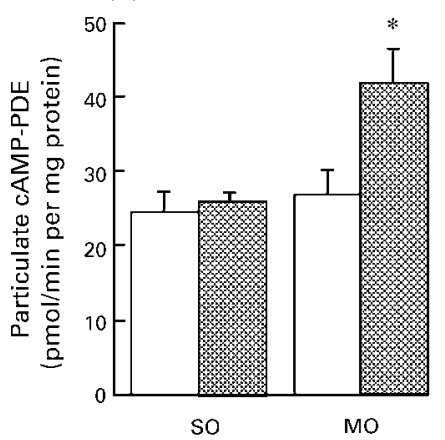

(b)

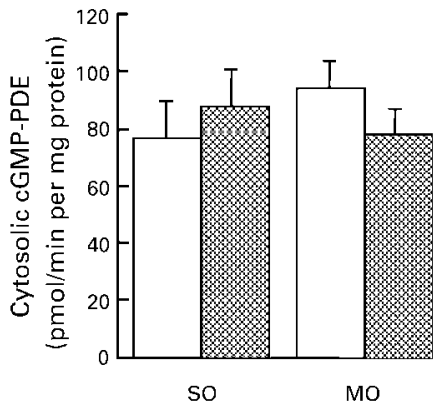

(d)

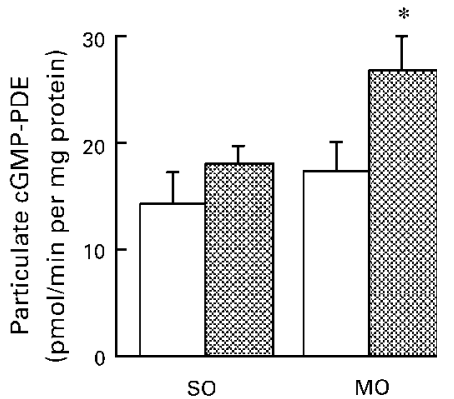

Fig. 2. Effects of marine oil (MO, $600 \mathrm{mg} / \mathrm{d}$ for 6 weeks) $v$. sunflower oil (SO (placebo), $600 \mathrm{mg} / \mathrm{d}$ for 6 weeks) on cAMP and cGMP-phosphodiesterase (PDE) activities of peripheral blood mononuclear cells in elderly subjects. Cytosolic CAMP- (a) and cGMP-PDE (b) activities, and particulate CAMP- (c) and cGMP-PDE (d) activities were assayed in the presence of $0.25 \mu \mathrm{M}$-CAMP or -cGMP as the substrate. ( $\square$ ), day 0; (B), day 42). For details of subjects and procedures, see p. 524. Values are means with their standard errors represented by vertical bars for ten subjects per group. Mean values were significantly different from those at day 0 (Student's $t$ test): ${ }^{\star} P \leq 0.05$.

(DHA + EPA) causes immunosuppression. However, there is little information about the influence of very low doses of these fatty acids on immune function, especially in human subjects. Results of the present study show that even $n$-3 PUFA doses as low as $180 \mathrm{mg} / \mathrm{d}$ for 6 weeks are sufficient to markedly decrease the proliferative response of lymphocytes to mitogenic lectins and antigens. These results are in good agreement with those of a recent animal study showing that diets containing 20-25\% of the level of EPA and DHA found in fish oil exert

(a)

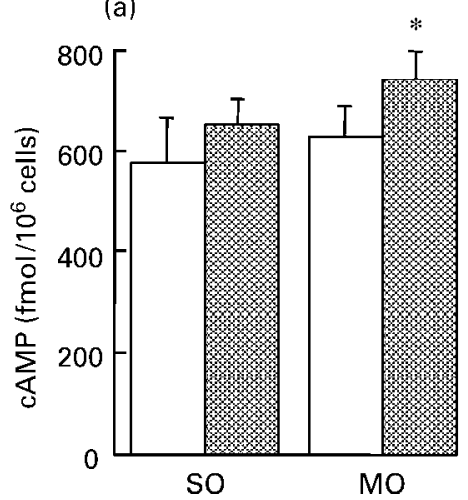

immunosuppressive effects similar to those of fish oil (Peterson et al. 1998). They are also in agreement with results from Thies et al. (2001), who have reported a significant reduction in the mitogenic responses to concanvalin A in subjects consuming $720 \mathrm{mg}$ EPA $+280 \mathrm{mg} \mathrm{DHA} /$ d. Because these authors could not observe a significant effect on lymphocyte response with $720 \mathrm{mg}$ of DHA alone, it can be speculated that the effect of $n$-3 fatty acids on immune responses was due to EPA. However, in the experiments reported here, the MO used for the

(b)

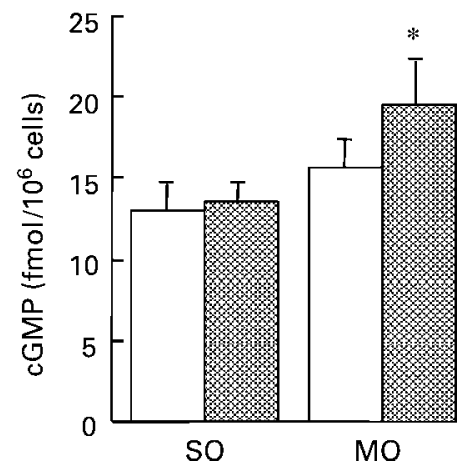

Fig. 3. Effects of marine oil (MO, $600 \mathrm{mg} / \mathrm{d}$ for 6 weeks) $v$. sunflower oil (SO (placebo), $600 \mathrm{mg} / \mathrm{d}$ for 6 weeks) on the cyclic nucleotide levels

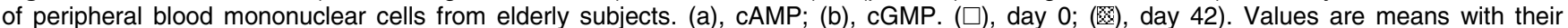
standard errors represented by vertical bars for ten subjects per group. For details of subjects and procedures, see p. 524. Mean values were significantly different from those at day 0 (Student's $t$ test): * $P \leq 0.05$. 


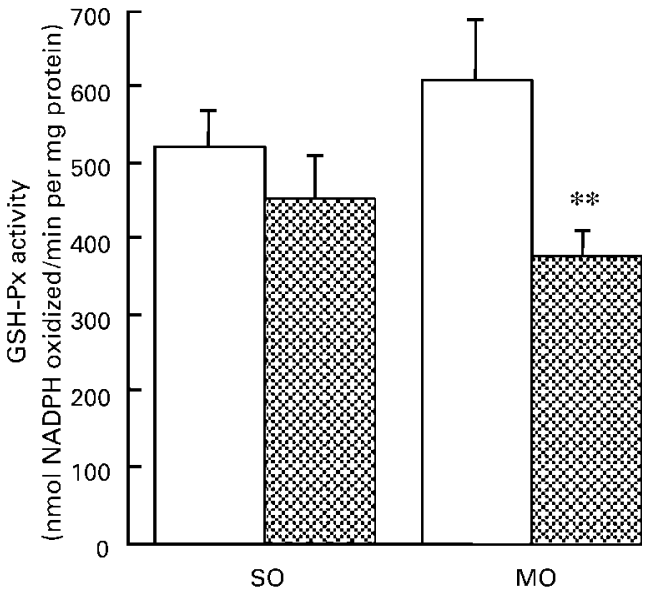

Fig. 4. Effects of marine oil (MO, $600 \mathrm{mg} / \mathrm{d}$ for 6 weeks) $v$. sunflower oil (SO (placebo), $600 \mathrm{mg} / \mathrm{d}$ for 6 weeks) on the glutathione peroxidase (GSH-Px) activities of peripheral blood mononuclear cells from elderly subjects. ( $\square$ ), day 0 ; (国), day 42). Values are means with their standard errors represented by vertical bars for ten subjects per group. For details of subjects and procedures, see p. 524. Mean values were significantly different from those at day 0 (Student's $t$ test): ${ }^{\star *} P \leq 0.01$.

supplementation contained 5-fold more DHA than EPA. Furthermore, we only observed significant DHA enrichment in plasma cholesteryl esters and platelet PE $(P<0.002)$ (Véricel et al. 1999) with no variation in the EPA content of plasma and platelet lipids. Taken together, these observations suggest that the impairment of the lymphoproliferative response was very probably attributable to DHA, at variance with the study of Thies et al. (2001).

Cyclic nucleotides are well recognized as major intracellular regulators of growth especially in lymphocytes, where cAMP potently inhibits proliferation. The decreased proliferative response observed in the MO group may be due to the slight but significant $(P<0.05)$ rise in intracellular cAMP levels. Moreover, the slight lowering of the cytosolic PDE activities might be partially responsible for the cyclic nucleotide level increase. At the same time, the particulate PDE activities were markedly and significantly enhanced in the MO group $(+56-57 \%)$. Both decreased cytosolic and increased particulate PDE activities suggest that $n$-3 PUFA are able to favour the translocation of the cytosolic enzymes to the membrane, thus leading to a less efficacious hydrolysis of cyclic nucleotides in the cytosol.

Although some of the effects of $n$-3 PUFA on immune cell functions are readily explained by a decrease in membrane arachidonic acid level and a concomitant decrease in eicosanoid production (Miles \& Calder, 1998), such a mechanism can be ruled out, as the fatty acid composition of plasma and platelet lipids was only minimally modified.

Alternative hypotheses have correlated the inhibitory effect of PUFA on lymphocyte proliferation with peroxidation. However, contradictory results regarding the influence of the antioxidant vitamins $\mathrm{C}$ and $\mathrm{E}$ on the immunosuppressive effect of $n-3$ fatty acids have been reported. While some groups have found that the suppressive effect of $n-3$ fatty acids was prevented by vitamin $\mathrm{E}$ both in vivo and in vitro (Kramer et al. 1991; Kumar et al. 1992; Meydani, 1996), other studies have shown that antioxidants failed to reverse the inhibitory effect of DHA and EPA on lymphocyte proliferation (Calder \& Newsholme, 1992, 1993; Joulain et al. 1995). In the present study, both SO and MO supplements contained adequate amounts of vitamin E, as calculated according to Muggli (1989). Thus, it can be concluded that non-specific lipid peroxidation is not likely to be involved in the DHA + EPA suppressive effect.

In most human nutritional studies, the enrichment of cell membranes with $n-3$ fatty acids after fish oil intake has been reported to increase GSH-Px activity, possibly due to increased amount of cellular lipid hydroperoxides (Bellisola et al. 1992). Some authors of in vitro studies have also reported increased GSH-Px activity after treatment of human PBMN (Joulain et al. 1994), platelets (Lemaitre et al. 1997) or vascular endothelial cells (Crosby et al. 1996) with $n-3$ fatty acids. The results of the present study show that the dietary supplementation of healthy elderly people with very low doses of $n-3$ fatty acids did not increase PBMN GSH-Px activity, but even significantly $(P<0.01)$ reduced it by $38 \%$. Increased GSH-Px activity may be considered as an adaptative response to an enhanced generation of lipid hydroperoxides, as suggested by Bellisola et al. (1992), and the present results suggest that the low doses of $n-3$ fatty acids used might prevent lipid peroxidation by a mechanism that remains presently unknown. This proposal is supported by results from Véricel et al. (1999), who showed a significant increase of $\alpha$ - and $\gamma$-tocopherol, with a concomitant decrease of malondialdehyde, in platelets of elderly people supplemented for 6 weeks with low doses of MO. We have recently reported (Bechoua et al. 1999) that DHA was able to prevent malondialdehyde production induced by low $\mathrm{H}_{2} \mathrm{O}_{2}$ concentrations in human PBMN. Thus, it is conceivable that DHA also decreased the production of lipid hydroperoxides in PBMN of elderly people after supplementation with $\mathrm{MO}$, leading to a down-regulation of the GSH-Px enzyme. Whether the decreased GSH-Px activity is related to the suppressive effect of DHA + EPA on lymphocyte proliferation or not remains unclear, as both prooxidant and antioxidant states are required sequentially at different period of times during lymphocyte activation (Dröge et al. 1991).

Finally, $n-3$ fatty acids may also interfere with signal transduction pathways involved in lymphocyte activation. In a previous in vitro study (Bechoua et al. 1998), we have observed a decreased production of the phosphatidic acid (PA) mass in DHA-treated cells stimulated by concanavalin A as compared with untreated cells. Because PA is a potent mitogen, a decrease of its intracellular production may be responsible for the inhibition of the lymphoproliferative response observed in the elderly subjects supplemented with MO.

\section{Acknowledgements}

This work was funded by INSERM and the Région Rhône-Alpes. S. B. was a recipient of a fellowship from 
the Région Rhône-Alpes. We gratefully thank Imedex and Thallia Pharmaceuticals, especially Drs J. L. Tayot and Y. Bayon for providing the oil preparations. We thank the nurses of the Hôpital des Charpennes for their assistance and the participants for their cooperation. We are especially grateful to Dr J. F. Pageaux for helpful advice about the statistical analysis of the data.

\section{References}

Agence Française de Sécurité Sanitaire des Aliments Establissement public de l'Etat, Maisons-Alfort, France.

Alexander-North LS, North JA, Kiminyo KP, Buettner GR \& Spector AA (1994) Polyunsaturated fatty acids increase lipid radical formation induced by oxidant stress in endothelial cells. Journal of Lipid Research 35, 1773-1785.

Ayala A \& Chaudry IH (1995) Dietary $n-3$ polyunsaturated fatty acid modulation of immune cell function before or after trauma. Nutrition 11, 1-11.

Bechoua S, Dubois M, Dominguez Z, Goncalves A, Némoz G, Lagarde M \& Prigent AF (1999) Protective effect of docosahexaenoic acid against hydrogen peroxide induced oxidative stress in human lymphocytes. Biochemical Pharmacology 57, $1021-1030$

Bechoua S, Dubois M, Némoz G, Lagarde M \& Prigent AF (1998) Docosahexaenoic acid lowers phosphatidate level in human activated lymphocytes despite phospholipase D activation. Journal of Lipid Research 39, 873-883.

Beckman KB \& Ames BN (1998) The free radical theory of aging matures. Physiological Reviews 78, 547-581.

Bellisola G, Galassini S, Moschini G, Poli G, Perona G \& Guidi GC (1992) Selenium and glutathione peroxidase variations induced by polyunsaturated fatty acid oral supplementation in humans. Clinica Chimica Acta 205, 75-85.

Boukhchache D \& Lagarde M (1982) Interaction between prostaglandin precursors during their oxygenation by human platelets. Biochimica et Biophysica Acta 713, 386-392.

Bradford MM (1976) A rapid and sensitive method for the quantification of microgram quantities of protein utilizing the principle of protein-dye binding. Analytical Biochemistry 72, 248-254.

Burns EA \& Goodwin JS (1997) Immunodeficiency of aging. Drugs and Aging 11, 374-397.

Calder PC \& Newsholme EA (1992) Polyunsaturated fatty acids suppress human peripheral blood lymphocyte proliferation and interleukin-2 production. Clinical Science 82, 695-700.

Calder PC \& Newsholme EA (1993) Influence of antioxidant vitamins on fatty acid inhibition of lymphocyte proliferation. Biochemistry and Molecular Biology International 29, 175-183.

Calder PC, Yaqoob P, Thies F, Wallace FA \& Miles EA (2002) Fatty acids and lymphocyte functions. British Journal of Nutrition 87, 831-848.

Calzada C, Véricel E \& Lagarde M (1992) Lower levels of lipid peroxidation in human platelets incubated with eicosapentaenoic acid. Biochimica et Biophysica Acta 1127, $147-152$

Crosby AJ, Wahle KWJ \& Duthie GG (1996) Modulation of glutathione peroxidase activity in human vascular endothelial cells by fatty acids and cytokine interleukin-1ß. Biochimica et Biophysica Acta 1303, 187-192.

Croset M, Véricel E, Rigaud M, Hanss M, Courpron P, Dechavanne M \& Lagarde M (1990) Functions and tocopherol content of blood platelets from elderly people after low intake of purified eicosapentaenoic acid. Thrombosis Research 57, $1-12$

Dröge W, Eck H-P, Gmünder H \& Mihm S (1991) Requirement for prooxidant and antioxidant states in $\mathrm{T}$ cell mediated immune responses. Relevance for the pathogenic mechanism of AIDS? Klinische Wochenschrift 69, 1119-1122.

Endres S, De Caterina R, Schmidt EB \& Kristensen SD (1995) n-3 Polyunsaturated fatty acids: update. European Journal of Clinical Investigation 25, 629-638.

Endres S, Meydani SN, Ghorbani R, Schindler R \& Dinarello CA (1993) Dietary supplementation with $n-3$ fatty acids suppresses interleukin-2 production and mononuclear cell proliferation. Journal of Leukocyte Biology 54, 599-603.

Fortin PR, Lew RA, Liang MH, Wright EA, Beckett LA, Chalmers TC \& Sperling RI (1995) Validation of a meta analysis: the effects of fish oil in rheumatoid arthritis. Journal of Clinical Epidemiology 48, 1379-1390.

Joulain C, Guichardant M, Lagarde M \& Prigent AF (1995) Influence of polyunsaturated fatty acids on lipid metabolism in human blood mononuclear cells and early biochemical events associated with lymphocyte activation. Journal of Lipid Mediators and Cell Signalling 11, 63-79.

Joulain C, Prigent AF, Némoz G \& Lagarde M (1994) Increased glutathione peroxidase activity in human blood mononuclear cells upon in vitro incubation with $\omega-3$ fatty acids. Biochemical Pharmacology 47, 1315-1323.

Kariv I, Ferguson FG \& Confer FL (1992) Age- and strain-related differences in murine spleen cell responses to different activation signals. Cellular Immunology 140, 67-80.

Kramer TR, Schoene N, Douglass LW, Judd JT, Ballard-Barbash R, Taylor PR, Bhagavan HN \& Nair PP (1991) Increased vitamin $\mathrm{E}$ intake restores fish-oil-induced suppressed blastogenesis of mitogen-stimulated $\mathrm{T}$ lymphocytes. American Journal of Clinical Nutrition 54, 896-902.

Kumar GS, Das UN, Kumar KV, Madhavi N, Das NP \& Tan BKH (1992) Effect of $n-6$ and $n-3$ fatty acids on the proliferation of human lymphocytes and their secretion of TNF- $\alpha$ and IL-2 in vitro. Nutrition Research 12, 815-823.

Lemaitre D, Véricel E, Polette A \& Lagarde M (1997) Effects of fatty acids on human platelet glutathione peroxidase: possible role of oxidative stress. Biochemical Pharmacology 53, 479-486.

Meskini N, Hosni M, Némoz G, Lagarde M \& Prigent AF (1992) Early increase in lymphocyte cyclic nucleotide phosphodiesterase activity upon mitogenic activation of human peripheral blood mononuclear cells. Journal of Cellular Physiology 150, 140-148.

Meskini N, Macovschi O, Prigent AF, Némoz G, Chapuy P \& Lagarde M (1990) Decreased cyclic nucleotide phosphodiesterase activity in human peripheral blood mononuclear cells from elderly women. Clinical Science 79, $467-470$

Meskini N, Némoz G, Chapuy P, Haond P, Pageaux JF, Véricel E, Lagarde M \& Prigent AF (1993) Glutathione peroxidase activity and metabolism of arachidonic acid in peripheral blood mononuclear cells from elderly subjects. Clinical Science 85, 203-211.

Meydani SN (1996) Effect of ( $n$-3) polyunsaturated fatty acids on cytokine production and their biologic function. Nutrition 12, Suppl., S8-S14.

Miles EA \& Calder PC (1998) Modulation of immune function by dietary fatty acids. Proceedings of the Nutrition Society 57, 277-292.

Mohan IK \& Das UN (1997) Oxidant stress, anti-oxidants and essential fatty acids in essential fatty acids in systemic lupus erythematosus. Prostaglandins, Leukotrienes and Essential Fatty Acids 56, 193-198. 
Muggli RD (1989) Dietary oils increase the requirements for vitamin in human. In Health Effects of Fish and Fish Oils, pp. 201-210 [RK Chandra, editor]. St John's, Newfoundland: Arts Biomedical Publishers.

Murphy MG (1990) Dietary fatty acids and membrane protein function. Journal of Nutritional Biochemistry 1, 68-79.

Nair PP, Judd JT, Berlin E, Taylor PR, Shami S, Sainz E \& Bhagavan HN (1993) Dietary fish oil-induced changes in the distribution of alpha-tocopherol, retinol, and beta-carotene in plasma, red blood cells, and platelets: modulation by vitamin E. American Journal of Clinical Nutrition 58, 98-102.

Paglia DE \& Valentine WN (1967) Studies on the quantitative and qualitative characterization of erythrocyte glutathione peroxidase. Journal of Laboratory and Clinical Medicine 70, $158-169$.

Peterson LD, Thies F, Sanderson P, Newsholme EA \& Calder PC (1998) Low level of eicosapentaenoic and docosahexaenoic acids mimic the effects of fish oil upon rat lymphocytes. Life Sciences 62, 2209-2217.

Rose DP (1997) Effects of dietary fatty acids on breast and prostate cancers: evidence from in vitro experiments and animal studies. American Journal of Clinical Nutrition 66, Suppl., $1513 \mathrm{~S}-1522 \mathrm{~S}$.
Simopoulos PA (1991) Omega-3 fatty acids in health and disease and in growth and development. American Journal of Clinical Nutrition 54, 438-463.

Skalhegg BS, Landmark BF, Doskeland SO, Hansson V, Lea T \& Jahnsen T (1992) Cyclic AMP-dependent protein kinase type I mediates the inhibitory effects of $3^{\prime}, 5^{\prime}$-cyclic adenosine monophosphate on cell replication in human $\mathrm{T}$ lymphocytes. Journal of Biological Chemistry 267, 15707-15714.

Solana R, Villanueva JL, Pena J \& De la Fuente M (1991) Cell mediated immunity in ageing. Comparative Biochemistry and Physiology 99A, 1-4.

Thies F, Nebe-von-Caron G, Powell JR, Yaqoob P, Newsholme EA \& Calder PC (2001) Dietary supplementation with $\gamma$-linolenic acid or fish oil decreases $\mathrm{T}$ lymphocyte proliferation in healthy older humans. Journal of Nutrition 131, 1918-1927.

Tian L, Cai Q \& Wei H (1998) Alterations of antioxidant enzymes and oxidative damage to macromolecules in different organs of rats during aging. Free Radical in Biology and Medicine 24, 1477-1484.

Véricel E, Calzada C, Chapuy P \& Lagarde M (1999) The influence of low intake of $n-3$ fatty acids on platelets in elderly people. Atherosclerosis 147, 187-192. 